\title{
Transient Model Validation of Fixed-Speed Induction Generator Using Wind Farm Measurements
}

Rogdakis, Georgios; Garcia-Valle, Rodrigo; Arana Aristi, Iván

Published in:

IEEE Transactions on Power Systems

Link to article, DOI:

10.1109/TPWRS.2011.2168832

Publication date:

2012

Link back to DTU Orbit

Citation (APA):

Rogdakis, G., Garcia-Valle, R., \& Arana Aristi, I. (2012). Transient Model Validation of Fixed-Speed Induction Generator Using Wind Farm Measurements. IEEE Transactions on Power Systems, 27(1), 564-571.

https://doi.org/10.1109/TPWRS.2011.2168832

\section{General rights}

Copyright and moral rights for the publications made accessible in the public portal are retained by the authors and/or other copyright owners and it is a condition of accessing publications that users recognise and abide by the legal requirements associated with these rights.

- Users may download and print one copy of any publication from the public portal for the purpose of private study or research.

- You may not further distribute the material or use it for any profit-making activity or commercial gain

- You may freely distribute the URL identifying the publication in the public portal

If you believe that this document breaches copyright please contact us providing details, and we will remove access to the work immediately and investigate your claim. 


\title{
Transient Model Validation of Fixed-Speed Induction Generator Using Wind Farm Measurements
}

\author{
Georgios Rogdakis, Rodrigo García-Valle, Member, IEEE, and Iván Arana, Member, IEEE
}

\begin{abstract}
In this paper, an electromagnetic transient model for fixed-speed wind turbines equipped with induction generators is developed and implemented in PSCAD/EMTDC. The model is comprised by: an induction generator, aerodynamic rotor, and a two-mass representation of the shaft system. Model validation is conducted by measurement comparison using recordings obtained from switching operations performed at the Nysted Offshore Wind Farm in Denmark. A sensitivity analysis is performed to determine the impact of different model parameters on the simulated response as compared with measurements. This validated model will be used for assessing induced overvoltage conditions that may arise under switching operations similar to those captured by the measurements used for validation.
\end{abstract}

Index Terms-Current measurements, induction generators, modeling, switching transient voltage measurements, wind turbines.

\section{INTRODUCTION}

$\mathbf{T}$ HE wind power capacity in Denmark is currently estimated to be more than $3000 \mathrm{MW}$ [1]; this figure accounts for both onshore and offshore wind farms, with the latter experiencing a large growth during the recent years. Denmark is one of the largest developers of offshore wind farms and, by $2009,660 \mathrm{MW}$ of offshore wind turbines were connected to the Danish grid [1]. The offshore wind energy capacity is expected to grow even more in the coming years, particularly considering the forthcoming commissioning of the 400 MW Anholt Offshore Wind Farm in 2013 [1]. By 2030, it is expected that the wind power capacity in Denmark will reach about $5500 \mathrm{MW}$, of which $4000 \mathrm{MW}$ will be supplied by offshore wind farms [2].

The ongoing strenuous wind power integration requires large offshore wind farms to become a significant part of the system's power supply; as a consequence, the system operation will be heavily reliant on wind power generation. To ensure overall stability of the grid during and after network faults, system operators have introduced severe rules for the operation of wind turbines in the course of fault events. These operation practices are included in grid codes [3]-[5] where specifications detail the conditions under which wind farms are required to re-

Manuscript received April 13, 2011; revised August 11, 2011; accepted September 11, 2011. Paper no. TPWRS-00323-2011.

G. Rogdakis and I. Arana are with DONG Energy, Copenhagen, Denmark (e-mail: georo@gondenergy.dk; ivaar@dongenergy.dk).

R. García-Valle is with the Centre for Electric Technology, Department of Electrical Engineering, Technical University of Denmark, 2800 Lyngby, Denmark (e-mail:rgv@elektro.dtu.dk).

Color versions of one or more of the figures in this paper are available online at http://ieeexplore.ieee.org.

Digital Object Identifier 10.1109/TPWRS.2011.2168832 main connected to the system. A wind turbine's ability to maintain uninterrupted operation during and after faults is known as "low voltage fault ride-through capability". A voltage decrease at the point of common coupling (PCC), which will take place during faults, will lead to the acceleration of wind turbines. Depending on the severity of the fault, the impact on the stability of the wind farm will vary. However, if reactive power compensation and blade-angle control is used, voltage stability and fault ride-through capability may improve [6], [7].

In addition, the Danish grid code [3] specifies the allowed levels of temporary overvoltage acceptable when wind farms are isolated from the grid. Fixed-speed wind turbines in island operation furnished with reactive power compensation tend to increase the voltage at the PCC [8], [9]. In addition, when the wind turbines are disconnected from the grid, due to the loss of the load, their electrical speed will increase. As it will be described and represented later in the paper, in the fixed-speed wind turbines, there is a strong coupling between the electrical and mechanical parameters. Therefore, an increase in the electrical speed will lead in the increase of the mechanical speed. While the wind turbines remain in island operation, their speed will rise until it reaches the over-speed limit that will stop their operation [10].

This paper proposes a model for fixed-speed wind turbines which is capable of reproducing temporary transient overvoltages as a product of the switching operation in wind farm radial feeders. The model developed is validated through the comparison of the model's response with voltage and current measurements taken from the Nysted Offshore Wind Farm (NOWF) in Denmark. NOWF consists of 72 wind turbines, each with a rated power of $2.3 \mathrm{MW}$, and was commissioned in December 2003 [11]. The wind turbines at NOWF are fixed-speed active-stall and are equipped with squirrel-cage induction generators. The wind farm is divided into eight radial feeders, each with nine wind turbines, which are connected to the grid through a three-winding transformer (180/90/90MVA; 132/33/33 kV).

A GPS-synchronized measuring system was developed and installed at NOWF [12], and field measurements were obtained in 2007. This system captured high frequency transients from the voltage and the current measurements simultaneously at three different locations of the collection grid. This was possible given the high sampling rate of $2.5 \mathrm{MHz}$ of the measuring devices. The measuring points were located at [12]:

- the main transformer on the offshore platform, after the circuit breaker of radial feeder A;

- the first wind turbine in radial feeder A, A01;

- the last wind turbine in radial feeder A, A09. 


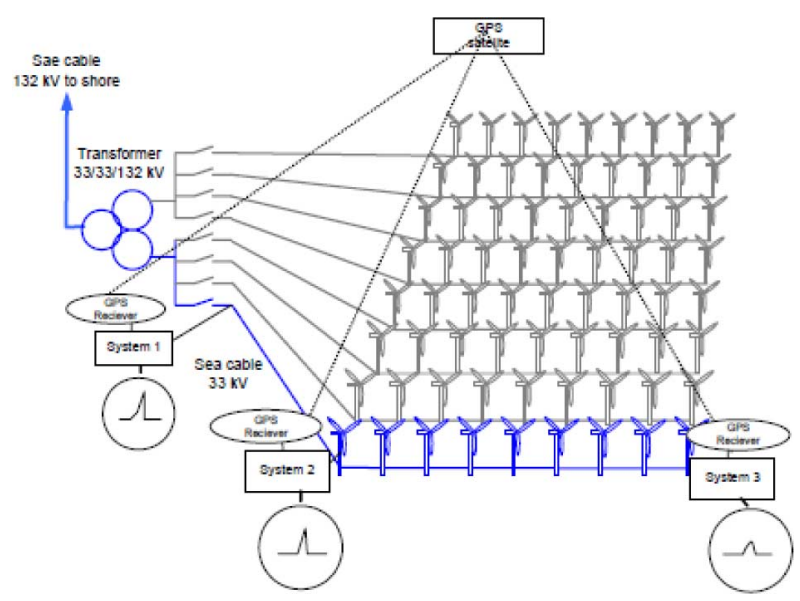

Fig. 1. Locations of the GPS-synchronized measuring devices at NOWF.

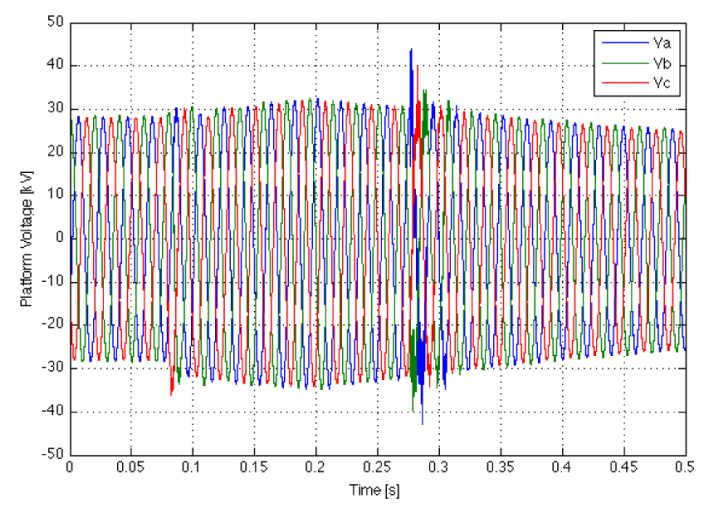

Fig. 2. Measured three phase voltages at the transformer platform in radial feeder A during the switching operation.

The measuring points and the layout of the wind farm are shown in Fig. 1. Several switching transients were captured.

However, in this paper, only the disconnection of the radial feeder A is investigated. Fig. 2 shows the three phase voltages measured, while Fig. 3 shows the corresponding current measurements during one of these switching operations. Note that the wind turbines were in operation at the time of the measurements used in this study. The switching operation of radial feeder A occurs at $0.08 \mathrm{~ms}$; the current to the transformer drops to zero immediately. Nevertheless, there is a small amount of current flowing between wind turbines A01 and A09, showing that the wind turbines remain connected after disconnection of the radial feeder. Even though it is not presented here, it should be mentioned that after those $500 \mathrm{~ms}$, the voltage decreases until it reaches zero. The current at the transformer platform remains zero, which reveals that the feeder does not reconnect during the experiment, while the current at A01 and A09 drops to zero.

\section{Modeling}

With the aim of reproducing the observed behavior during the radial feeder switching, a fixed-speed wind turbine model was developed. Here the collection grid of the wind farm is also considered because the switching operation opened the radial feeder breaker. The collection grid consists of the high voltage (HV) and submarine cables linked to the PCC, the wind farm main
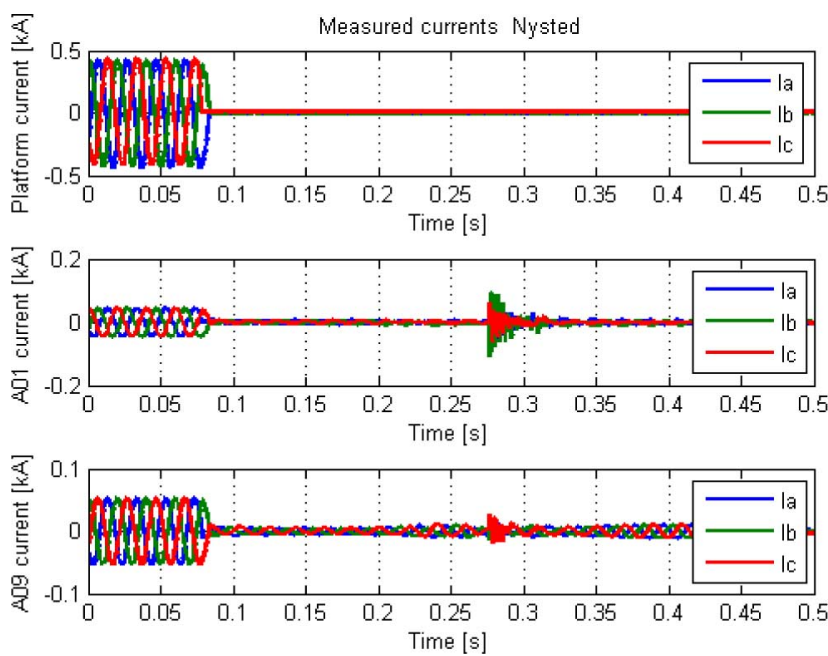

Fig. 3. Measured three-phase currents in radial feeder A during the switching operation. Upper plot: current at the platform. Middle plot: current at A01. Lower plot: current at A09.

transformer, the medium voltage (MV) submarine cable of radial A, and the wind turbine transformers. Modeling of NOWF's collection grid has been discussed previously in [13]. For the scope of this paper, the methodologies discussed in [13] were adopted. Thus, all cables were modeled as $\pi$-sections while the transmission grid was modeled as a voltage source with series impedance.

Each radial feeder is comprised by nine active-stall fixed-speed wind turbines equipped with squirrel-cage induction generators. This is the so-called "Danish concept" because the Danish wind turbine manufacturers implemented this configuration at many sites until the early 2000s [14]. Modeling of fixed-speed wind turbines for stability studies has been addressed in the open literature [7], [14]-[16]. In this study, the guidelines for modeling of fixed-speed wind turbines in [7] were followed. Hence, the model developed for the simulation of the switching event includes:

- aerodynamics of the wind turbine;

- shaft system of the wind turbine;

- squirrel-cage induction generator;

- blade-angle control;

- capacitor banks for reactive power compensation.

The model was implemented in PSCAD/EMTDC and simulations were performed using the software tool.

\section{A. Aerodynamics}

The aerodynamic properties of the wind turbine's rotor are represented by the power coefficient $C_{p}$, which determines the power delivered from the drive train to the generator. This coefficient depends on the tip speed ratio $\lambda$ and the pitch angle $\beta$. The tip speed ratio is related to the wind speed $V_{w}$, the rotor speed $\omega_{M}$, and the rotor radius $R$, as follows:

$$
\lambda=\frac{R \omega_{M}}{V_{w}} .
$$

Having determined the tip speed ratio, the mechanical power of the rotor can be determined from 


$$
P_{M}=\frac{1}{2}\left(\rho A C_{p}(\lambda, \beta) V_{W}^{3}\right)
$$

where $\rho_{\text {air }}$ is the air density equal to $1.225 \mathrm{~kg} / \mathrm{m}^{3}$ and $A$ is the swept area of the rotor equal to $A=\pi R^{2}$.

\section{B. Shaft System}

Several models are used for representing the shaft system, the most common being the lumped and the two-mass models. Due to the strong coupling between the mechanical and the electrical parameters of the generator, the wind turbine model requires the two-mass model representation of the shaft system [7]. In addition, to obtain realistic results in stability studies, [14] and [16] determine that the two-mass model and the fifth-order model of the induction generator provide better results than lumped models. The dynamics of the two-mass model are given by [7]

$$
\begin{aligned}
2 H_{M} \frac{d \omega_{M}}{d t} & =T_{M}-T_{G}-D_{M} \omega_{M} \\
2 H_{G} \frac{d \omega_{G}}{d t} & =T_{G}-T_{E}-D_{G} \omega_{G} \\
\frac{d \theta_{s}}{d t} & =\omega_{0}\left(\omega_{M}-\omega_{G}\right)
\end{aligned}
$$

where $H_{M}$ and $H_{G}$ are the inertia constants of the rotor and the generator, respectively; $T_{M}, T_{G}$, and $T_{E}$ are the mechanical torque of the rotor, the mechanical torque applied to the generator, and the electrical torque, respectively; $\omega_{M}$ and $\omega_{G}$ are the rotational speed of the rotor and the generator in that order; $\omega_{0}$ is the base speed of the power system; and $\theta_{s}$ is the twist of the shaft. The mechanical torque applied to the generator is given by [7]

$$
T_{G}=K_{s} \theta_{s}-D_{s}\left(\omega_{G}-\omega_{M}\right)
$$

where $K_{s}$ is the shaft stiffness. $D_{M}, D_{G}$, and $D_{s}$ are the damping coefficients of the rotor, the generator, and the shaft, respectively.

\section{Induction Generator}

The induction generator is represented using a fifth-order flux linkage model given by

$$
\begin{aligned}
& u_{D s}=R_{s} i_{D s}+\frac{d \lambda_{D s}}{d t}-\omega_{e} \lambda_{Q s} \\
& u_{Q s}=R_{s} i_{Q s}+\frac{d \lambda_{Q s}}{d t}-\omega_{e} \lambda_{D s} \\
& u_{D r}=R_{r} i_{D r}+\frac{d \lambda_{D r}}{d t}-\lambda_{Q r} \frac{d \theta_{r}}{d t} \\
& u_{Q r}=R_{r} i_{Q r}+\frac{d \lambda_{Q r}}{d t}+\lambda_{D r} \frac{d \theta_{r}}{d t} .
\end{aligned}
$$

The sub-indexes $s$ and $r$ stand for the generator's stator and rotor, respectively; while $u$ and $i$ indicate voltages and currents. The flux linkages of the stator and the rotor are represented by the variable $\lambda$. Note that this fifth-order model includes stator transients [7], [16].

\section{Blade-Angle Control}

Using an active-stall fixed-speed wind turbine, blade-angle control may be included. Blade-angle control is used for power output regulation at high wind speed. In addition, active-stall control may be activated when faults are detected in the system to assist the fault ride-through capabilities of the wind turbines. However, during faults, the wind turbine will operate as a conventional (passive) stall wind turbine due to the relatively slow response of the blade-angle control system [6], [17]. The simulations performed in this study have a total duration of $500 \mathrm{~ms}$, while the most significant transient events occur in less than 250 $\mathrm{ms}$. Therefore, it is possible to assume that the blade-angle control will not operate during the duration of the simulations, and consequently, it does not need to be included in the wind turbine model.

\section{E. Capacitor Banks}

Induction generator operation requires reactive power absorption. Increasing the turbine's active power output increases reactive power consumption. According to the Danish grid code, wind farms should be equipped with reactive power compensation to ensure that the reactive power stays within the specified limits [3]. In NOWF, wind turbines are equipped with capacitor banks to ensure reactive power compensation. Capacitor bank control is executed in two modes: power factor mode and the voltage control mode. While in power factor mode, the capacitor banks are controlled to ensure that the power factor is kept within the limits specified in the grid codes. For power factor mode operation, the voltage needs to be within limits. When these limits are exceeded, the capacitor banks are in voltage control mode. In this case, capacitor banks are disconnected or connected to ensure that the voltage remains within thresholds. In case voltage drops go below a critical point, all the available compensation should be connected immediately to support the voltage.

\section{VALIDATION}

In this section, the model validation is presented. The main events corresponding to the available measurements are the disconnection of radial feeder A and the high-transient overvoltage observed at $275 \mathrm{~ms}$. Here we assume that the transient overvoltage is due to the connection of capacitor banks. Noting that the recorded currents at wind turbines A01 and A09 are different, it is also possible to assume that the connection of capacitor banks occurs only at wind turbine A01. Under these assumptions, an initial scenario was designed and simulated.

The switching events and results of the base case simulation are those presented in [18]. Note that a significant discrepancy of the frequency of the measured and simulated voltage and current can be observed. This discrepancy was due to the lack of accurate information regarding the inertia constant of the wind turbine rotor $H_{M}$ and the shaft stiffness $K_{s}$. Even though the simulation provided acceptable results for validating the assumed scenario, further investigation was necessary. Values of the unspecified parameters of the initial scenario were obtained from 


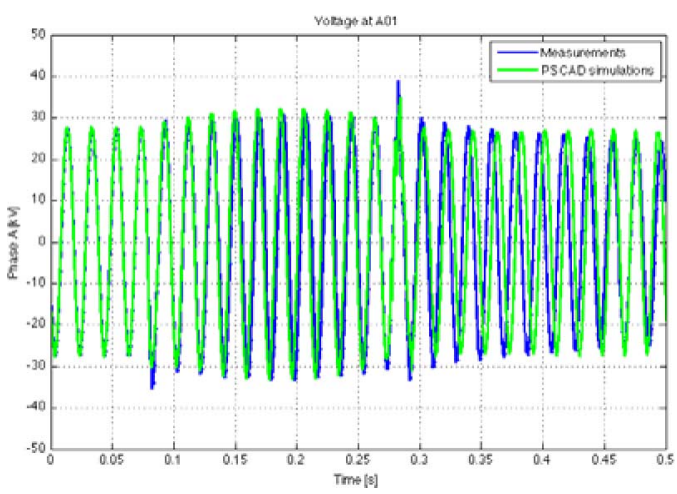

Fig. 4. Measured and simulated voltage at A01 from $0 \mathrm{~ms}$ to $500 \mathrm{~ms}$.
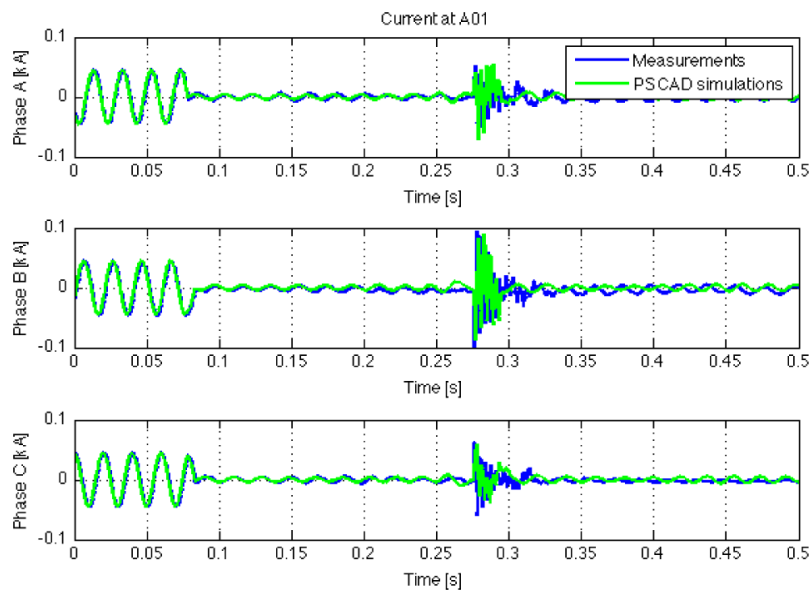

Fig. 5. Measured and simulated current at A0. Upper plot: Phase A. Middle plot: Phase B. Lower plot: Phase C.

[14]. Using these parameters, a new base case scenario was developed, for which results are presented in Figs. 4-6.

The voltage at wind turbine A01 is shown in Fig. 4, while the currents at A01 and A09 are depicted in Figs. 5 and 6, respectively. For the switching events, there was no difference between the original base case and the improved base case scenarios; moreover the transient overvoltages are similar. However, it can be observed that the enhancements made improve the agreement of the simulated voltage and current frequencies as compared to the measurements. There is still a small discrepancy after 330 $\mathrm{ms}$ because the parameters cannot be matched; however, these improvements provide a better model for fault ride-through capability studies.

The wind turbines of the radial feeder were in operation when the measurements were performed. In these simulations, the power output level was similar to the output of the wind turbines at the time of the switching as shown in Figs. 7 and 8. Active and reactive power computation was performed both from the measurements, and by transforming the voltages and the currents in the simulations to their sequence components [19]. The active power obtained in the simulation is similar to the active power captured by the measurements for the whole time frame. The reactive power is presented only for the steady state operation of the wind turbines and until the switching operation at $75 \mathrm{~ms}$. The reactive power is defined over a period; thus, calculation during
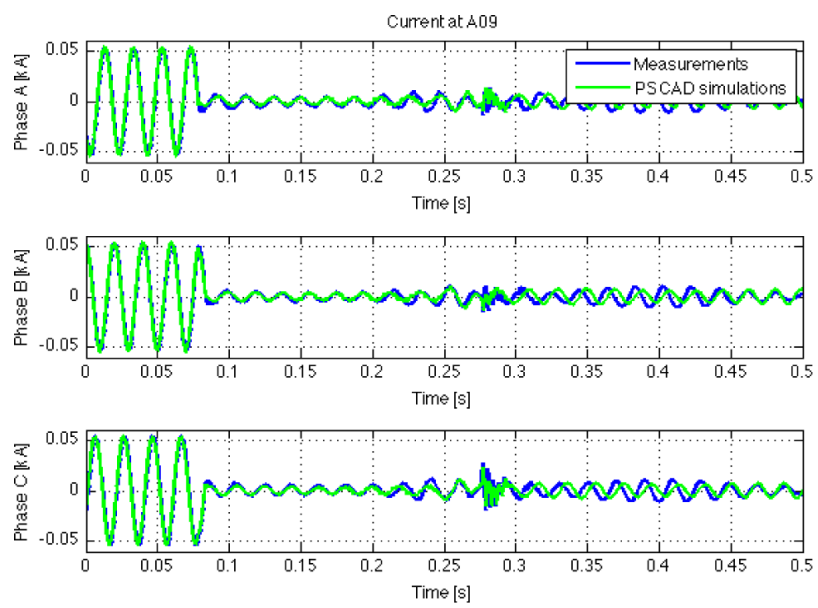

Fig. 6. Measured and simulated current at A09. Upper plot: Phase A. Middle plot: Phase B. Lower plot: Phase C.
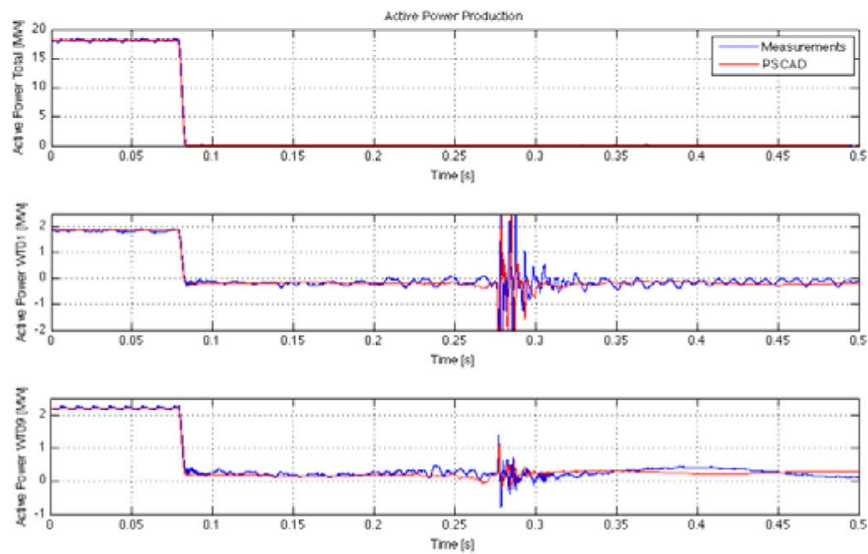

Fig. 7. Measured and simulated active power at the three measuring locations. Upper plot: Transformer platform. Middle plot: Wind turbine A01. Lower plot: Wind turbine A09.

transients does not have a physical meaning. A difference can be seen between the measurements and the simulations due to the instantaneous calculation; the measured reactive power fluctuates while the simulated reactive power is steady. In addition, at A01 and A09, the simulated reactive power is close to the measured but in the transformer platform is slightly different. However, it is considered that the simulated results are representative of the power production of the wind turbine.

\section{SENSITIVITY ANALYSIS}

In the previous section, results for the improved base case scenario were presented. The mechanical parameters of the wind turbine model were not specified. Therefore, a sensitivity analysis was carried out to estimate their values and represent the measurements as accurately as possible. A similar investigation in [20] discusses the effect product of the error of the measured value of the turbines. In addition, a sensitivity analysis on the wind turbine parameters is used in [21] to determine their effect on small signal stability.

In this study, sensitivity analysis is used to obtain unspecified parameters and produce a result closer to the reference measurements. In addition, their effect on temporary overvoltages is 

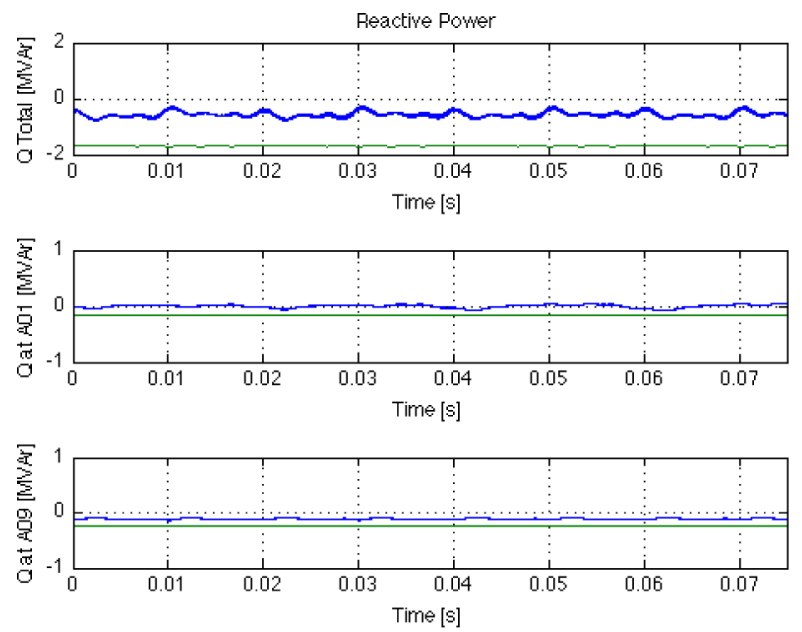

Fig. 8. Measured and simulated reactive power at the three measuring locations from $0 \mathrm{~ms}$ to $75 \mathrm{~ms}$. Upper plot: Transformer platform. Middle plot: Wind turbine A01. Lower plot: Wind turbine A09.

TABLE I

TyPical VAlues For Mechanical Parameters OF MODERN WIND TURBINES

\begin{tabular}{ccc}
\hline$H_{G},[s]$ & $H_{M},[s]$ & $K_{s},[p u / r a d]$ \\
$0.4-1$ & $2.5-12.5$ & $0.15-1.2$ \\
\hline
\end{tabular}

TABLE II

SCENARIOS BASED ON DIFFERENT VALUES FOR $H_{M}$ AND $K_{s}$

\begin{tabular}{lcc}
\hline & $H_{M},[s]$ & $K_{s},[\mathrm{pu} / \mathrm{rad}]$ \\
\hline Scenario A1 & 3.5 & 0.15 \\
Scenario A2 & 3.5 & 1.2 \\
Scenario A3 & 4.5 & 0.15 \\
Scenario A4 & 4.5 & 1.2 \\
\hline
\end{tabular}

discussed. In the original scenario [18], switching operations of capacitor banks were assumed. Here an additional investigation is performed to determine the effect of different switching operations' simulation results. The sensitivity analysis presented in this section consisted of:

- sensitivity analysis of the values of the inertia constant of wind turbine rotor and shaft stiffness;

- sensitivity analysis of different switching operations of capacitor banks.

\section{A. Mechanical Parameter Investigation}

In Table I. the typical values of inertia constants and the shaft stiffness are shown [7].

The inertia constant of the induction generator was given, so the sensitivity analysis is performed for the inertia constant of the wind turbine rotor $H_{M}$ and the shaft stiffness $K_{s}$. Due to the broad range of the parameters, the values from a similar wind turbine found in [14] were used as a starting point. Four scenarios were formulated with different values for $H_{M}$ and $K_{s}$, as shown in Table II.

Simulation results from the scenarios in Table II are presented in Fig. 9, where the positive sequence component of the voltage at wind turbine A01 is shown. The proposed sensitivity analysis shows that the shaft stiffness impacts overvoltages to a higher

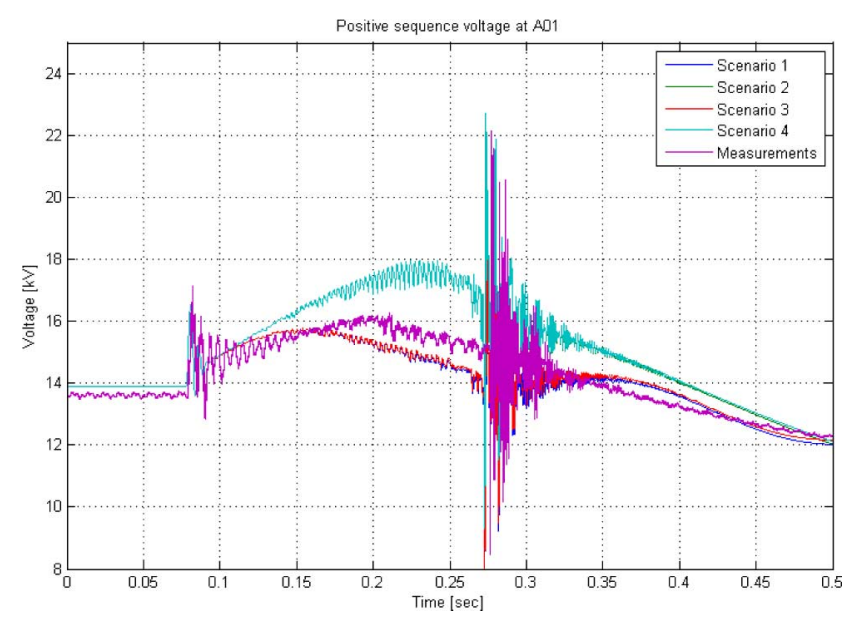

Fig. 9. Positive sequence voltage magnitude at A01. Comparison between all the scenarios of Table II and field measurements.

degree than the inertia of the rotor. For scenarios with the same shaft stiffness (A1 and A3, and A2 and A4), the waveform of the positive sequence voltage matches exactly. This finding can be explained by looking into the normal operation of fixed-speed wind turbines. During normal operation, the twisted shaft of the wind turbine accumulates potential energy [7]. The total energy is equal to

$$
W_{s}=\frac{1}{2} K_{s} \theta_{s}^{2}=\frac{1}{2} K_{s}\left(\frac{T_{M}}{K_{s}}\right)^{2}=\frac{1}{2} \frac{T_{M}^{2}}{K_{s}}
$$

where $\theta_{s}$ is the twist of the shaft under normal operation. When a fault occurs in the system, the twisted shafts start relaxing and potential energy is transferred to the generator's rotor. This leads to acceleration of the generator's rotation and more reactive power being absorbed from the grid. In this investigation, even though there is no fault in the grid, the islanding of the radial feeder leads to loss of power equilibrium. Hence, the wind turbine's mechanical system will act similarly to the case when there is a fault in the grid. In the range of values examined for the shaft stiffness, lower shaft stiffness will lead to higher potential energy accumulation. This is reflected in the voltage of wind turbine A01, where lower shaft stiffness provokes higher overvoltages.

\section{B. Switching Operations}

There are several uncertainties regarding the switching operations of the capacitor banks: First, it is uncertain what exactly happens after disconnection of radial feeder A, and secondly, the available measurements were made only at two wind turbines of the radial. Thus, even though it is possible to assume and verify the switching operations in the two measured wind turbines, for the other seven wind turbines assumptions were made. To minimize the degree of uncertainty, four scenarios were formulated by considering different switching operations at the capacitor banks. The rationale behind this sensitivity analysis is to determine plausible operations of capacitor banks in the wind turbines of the radial feeder as compared with the operations assumed in the base case scenario. The different scenarios considered are outlined in Table III. 
This article has been accepted for inclusion in a future issue of this journal. Content is final as presented, with the exception of pagination.

TABLE III

SWITCHING OPERATIONS OF THE CAPACITOR BANKS

\begin{tabular}{|c|l|}
\hline Scenario & \multicolumn{1}{c|}{ Switching operations } \\
\hline B1 & $\begin{array}{l}\text { Capacitor banks (15x90kVAr) switching operations occur at } \\
\text { A01 and A09. } \\
\text { Disconnection: 200ms/Connection: 275ms. }\end{array}$ \\
\hline B2 & $\begin{array}{l}\text { The capacitor banks (15x90kVAr) at all wind turbines are } \\
\text { operated as in scenario B1. Disconnections/connections are } \\
\text { done at the same times. Steps of 90kVAr. }\end{array}$ \\
\hline B3 & $\begin{array}{l}\text { No capacitor bank switching until } \mathrm{t}=275 \mathrm{~ms}, \text { when all are } \\
\text { disconnected (15x90kVAr). }\end{array}$ \\
\hline B4 & $\begin{array}{l}\text { Disconnection: 200ms/Connection: 275ms. Simultaneous steps } \\
\text { of 1x90kVAr, 1x180kVAr and 3x360kVAr. }\end{array}$ \\
\hline
\end{tabular}

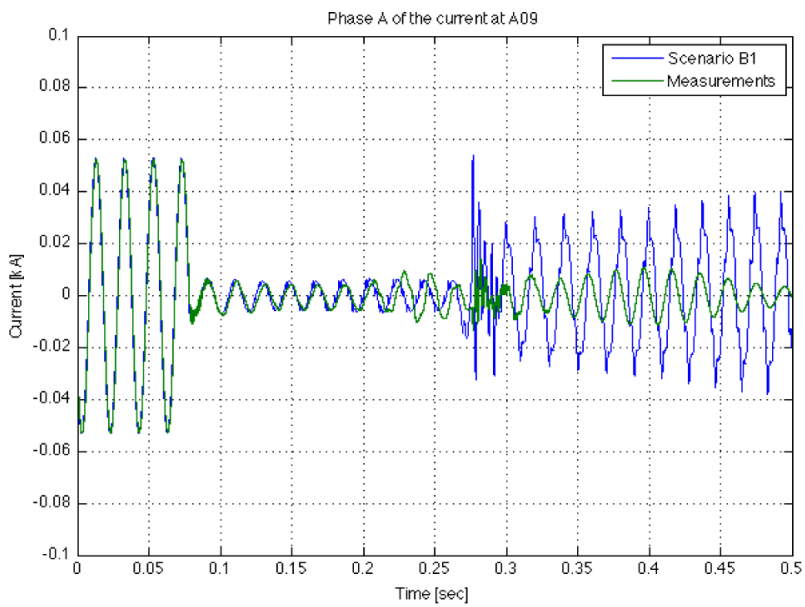

Fig. 10. Current: Phase A at A09. Comparison between scenario B1 and measurements at A09.

For the different scenarios in Table III, the voltages and currents are compared. The power output level is the same as in the base case scenario, while the mechanical parameters are the same in all scenarios. However, in this section, only the results that show the most important discrepancies are presented. The first simulated scenario is B1, where the main difference compared with the base case is that switching operations occur only at capacitor banks A01 and A09. Capacitor banks in other wind turbines, for which there are no available measurements, remain connected throughout the simulation. Fig. 10 shows the current magnitude for phase A at A09. The switching transients at $275 \mathrm{~ms}$ are higher in the simulation than in the measurements, while the current seems to increase after the switching operation. However, it is important to note that the frequency of the currents is very similar to the measurements.

In scenario B2, it is assumed that all the capacitor banks operate in the same way: they are disconnected at $200 \mathrm{~ms}$ and connected at $275 \mathrm{~ms}$. After the connection, the capacitor banks are disconnected again as in scenario B1. Fig. 11 depicts the voltage magnitude for phase A of A01. The resulting switching transients are more abrupt than those shown by the real measurements. Consequently, the simultaneous connection of the capacitor banks at $275 \mathrm{~ms}$ does not accurately represent the events captured by the measurements.

The previously simulated scenarios point to capacitor connection at $275 \mathrm{~ms}$ as the source of the switching transients at 275 ms. To confirm this assumption, in scenario B3, the capacitor banks are disconnected at this instant. The rationale behind this

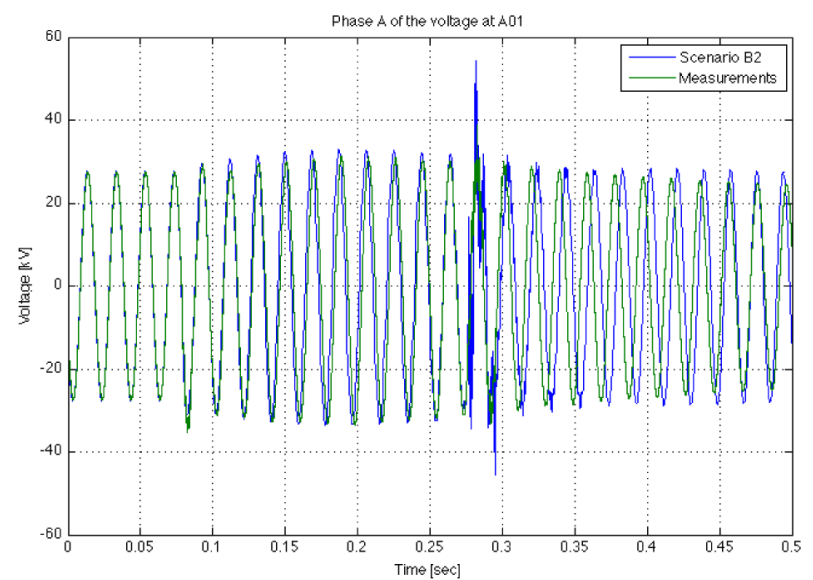

Fig. 11. Voltage of phase A at A01. Comparison between scenario B2 and measurements at $\mathrm{A} 01$.

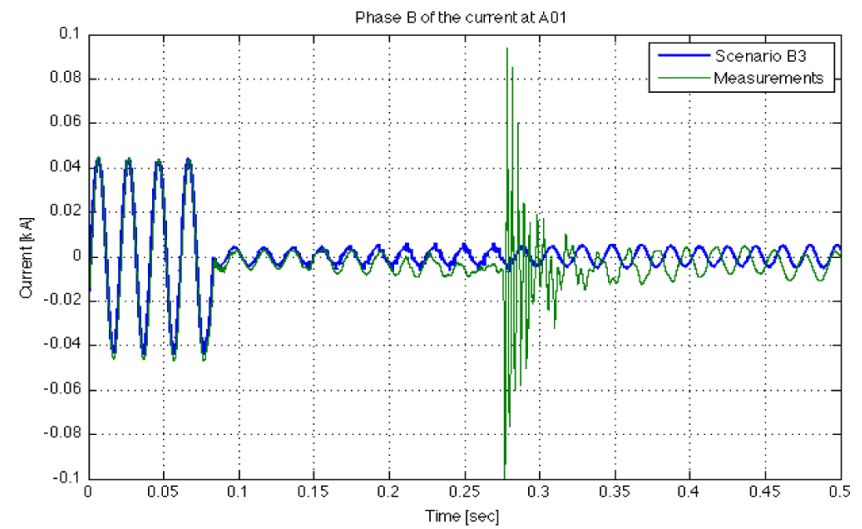

Fig. 12. Current for phase B at A01. Comparison between scenario B3 and field measurements at A01.

scenario is to check that a disconnection does not occur, hence all capacitor banks switch out simultaneously. In Fig. 12, the current magnitude of phase B at A01 is shown.

As it is depicted, the effect of the switching operation at 275 $\mathrm{ms}$ in the simulation is hardly noticeable. The disconnection of the capacitor banks has no effect on the current at A01. Therefore, even the worst case of disconnecting all the capacitor banks simultaneously does not represent the actual event.

Figs. 13 and 14 compare simulation results with measurements. In Scenario B4, the capacitor banks connect/disconnect at the same instant as in the improved base case scenario but in different steps. In all scenarios except for Scenario B4, the capacitor banks are considered as 15 steps of $90 \mathrm{kVAr}$; in Scenario $\mathrm{B} 4$, it is considered to be in teams of $1 \times 90 \mathrm{kVAr}, 1 \times 180$ $\mathrm{kVAr}$, and $3 \times 360 \mathrm{kVAr}$ as indicated in [22]. It is observed that the results from Scenario B4 are similar to the measurements. However, if they are also compared with the improved base case results, it can be seen that the oscillations in the voltage and the current have higher damping than in the improved base case.

Table IV shows RMS and instantaneous errors for the different scenarios at A01. The RMS error is computed for every phase over the entire simulation time. The values shown in Table IV are the sum error of the three phases. The error is substantial for the RMS voltage in all cases because of the 

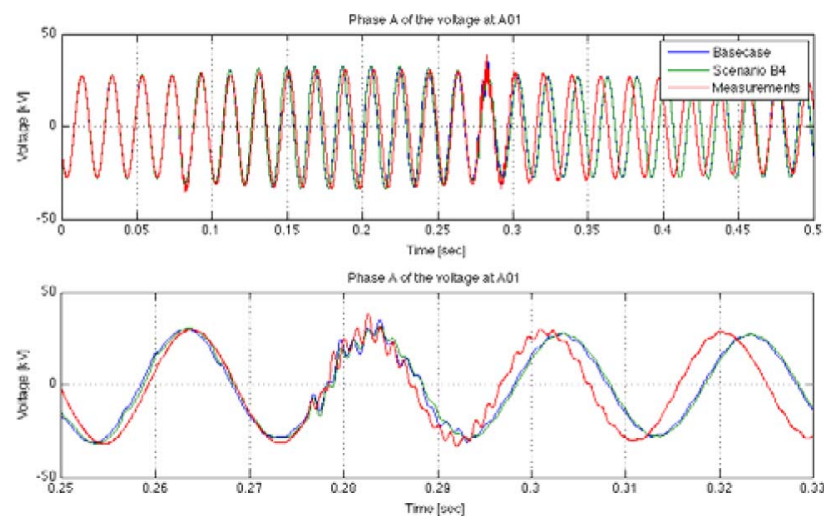

Fig. 13. Voltage of phase A at A01. Comparison between improved base case, scenario B4, and field measurements. Upper plot: Voltage phase A from 0 to $500 \mathrm{~ms}$. Lower plot: Voltage phase A from $250 \mathrm{~ms}$ to $300 \mathrm{~ms}$.
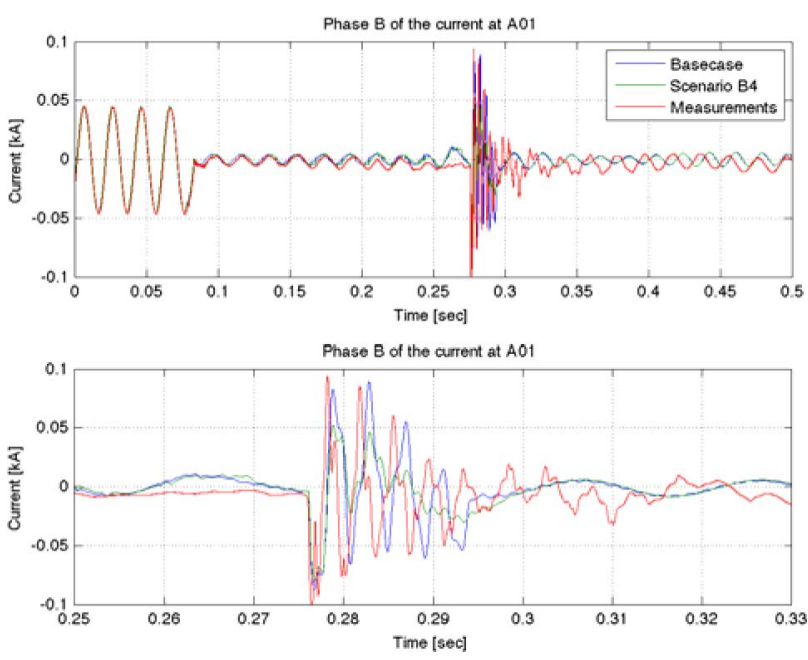

Fig. 14. Current magnitude for phase B at A01. Comparison between improved base case, scenario B4, and field measurements at A01. Upper plot: Current phase B from 0 to $500 \mathrm{~ms}$. Lower plot: Current phase B from $250 \mathrm{~ms}$ to $300 \mathrm{~ms}$.

phase shift after the switching operation at $275 \mathrm{~ms}$. In Table IV, the error of the instantaneous values of the voltage and the current at $275 \mathrm{~ms}$ is also shown, the smallest error in the results was obtained in the improved base case simulation. Thus, it is possible to conclude that the assumptions made for the improved base case are close to the events that occurred when the measurements were obtained.

\section{CONCLUSIONS}

In this paper, a model for fixed-speed wind turbines equipped with induction generators was introduced. These types of wind turbines have been used broadly in the past and are still present in several wind farms, including offshore farms. The model developed for electro-magnetic transient studies can be used for the assessment of temporary overvoltages induced after switching operations in wind farms.

The model consists of an induction generator, shaft, and the rotor's aerodynamics. During the validation of the model, the assumptions made on the wind turbine parameters and switching operations that occurred during the event led to an adequate representation of overvoltages. In addition, a sensitivity analysis
TABLE IV

ERroRs BETWEEN THE SimULATION RESUltS AND THE SimULATED SCENARIOS OF CAPACITOR SWITCHING AT A01

\begin{tabular}{ccccc}
\hline Scenario & $\begin{array}{c}\text { RMS } \\
\text { current } \\
\text { error, \% }\end{array}$ & $\begin{array}{c}\text { RMS } \\
\text { voltage } \\
\text { error, \% }\end{array}$ & $\begin{array}{c}\text { Instantaneous } \\
\text { current error, } \\
\%\end{array}$ & $\begin{array}{c}\text { Instantaneous } \\
\text { voltage error, } \\
\%\end{array}$ \\
\hline B1 & 104.2 & 169.7 & 142.8 & 51.7 \\
B2 & 55.5 & 140.8 & 261.5 & 150.6 \\
B3 & 55.3 & 137.8 & 347.7 & 72 \\
B4 & 68.3 & 136.2 & 128.6 & 121.5 \\
$\begin{array}{c}\text { Base } \\
\text { case }\end{array}$ & 70 & 129.5 & 108.6 & 28.1 \\
\hline
\end{tabular}

has revealed the influence of different wind turbine parameters on simulation results.

This study reveals that for the assessment of switching operations, blade-angle control may be neglected, as its response in this type of wind turbines is relatively slow. However, the mechanical components of the wind turbines have a significant impact on simulation results and must be included. Similarly, reactive power compensation equipment should be included in the model in conjunction with its control strategy.

However, it is also clear that the control of the reactive power compensation for assisting in complying with the fault ridethrough requirements of the grid codes is in conflict with the island operation of the wind turbines. When the fault ride-through is activated, reactive power will be furnished into the system in order to support the voltage. In island operation, because of the loss of torque the wind turbines will be accelerated and this will increase the voltage. Switching operations in the wind farms may lead to island operation; therefore, control strategies for reactive power compensation must assure that wind turbines respond accordingly to the specific situation and not include a generic control mode only for the fault ride-through.

\section{ACKNOWLEDGMENT}

The authors would like to thank DONG Energy for providing the measurements from the Nysted Offshore Wind Farm used in this investigation. The authors would also like to thank $\mathrm{L}$. Vanfretti for his valuable comments and for editing the paper.

\section{REFERENCES}

[1] Wind Turbines in Denmark, Danish Energy Agency, Tech. rep., 2009. [Online]. Available: http://www.ens.dk.

[2] B. Barton, C. Redgwell, A. Ronne, and D. N. Zillman, Managing Risk in a Dynamic Legal and Regulatory Environment, 1st ed. Oxford, U.K.: Oxford Univ. Press, 2004.

[3] Wind Turbines Connected to Grids With Voltages Above $100 \mathrm{kV}$, Energinet, Tech. rep., 2004.

[4] E.ON Netz. Grid Code- High and Extra High Voltage, E.ON Netz $\mathrm{GmbH}$, Tech. rep., 2006.

[5] National Grid. The Grid Code, National Grid Electricity Transmission plc, Tech. rep., 2010.

[6] V. Akhmatov, H. Knudsen, A. H. Nielsen, J. K. Pedersen, and N. K. Poulsen, "Modelling and transient stability of large wind farms," Elect. Power Energy Syst., vol. 25, pp. 123-144, 2003.

[7] Vladislav Akhmatov. Induction Generators for Wind Power. Essex, U.K.: Multi-Science, 2005

[8] P. Sorensen, A. D. Hansen, P. Christensen, M. Mieritz, J. Bech, B. Bak-Jensen, and H. Nielsen, Simulation and Verification of Transient Events in Large Wind Power Installations, Riso National Laboratory, Roskilde, Denmark, Tech. rep., 2003. 
[9] P. Sorensen, P. H. Madsen, A. Vikkelso, K. K. Jensen, K. A. Fathima, A. K. Unnikrishnan, and Z. V. Lakaparampil, Power Quality and Integration of Wind farms in Weak Grids in India Riso National Laboratory, Roskilde, 2000, Technical report.

[10] J. K. Pedersen, M. Akke, N. K. Poulsen, and K. O. H. Pedersen, "Analysis of wind farm islanding experiment," IEEE Trans. Energy Convers., vol. 15, no. 1, pp. 110-115, Mar. 2000.

[11] P. Volund, P. H. Pedersen, and P. E. Ter-Borch, "165 MW Nysted offshore wind farm. First year of operation performance as planned," in Proc. Eur. Wind Energy Conf. Exhib. (EWEC), 2004.

[12] L. S. Christensen, P. Sorensen, T. Sorensen, T. Olsen, and H. K. Nielsen, "GPS-synchronised high voltage measuring system," in Proc. Eur. Offshore Wind Conf., 2007.

[13] I. Arana, J. Holboll, A. H. Nielsen, O. Holmstrom, and T. Sorensen, "Voltage dip caused by the sequential energisation of wind turbine transformers," in Proc. Eur. Wind Energy Conf. Exhib., 2009.

[14] V. Akhmatov, "Analysis of dynamic behaviour of electric power systems with large amount of wind power," Ph.D. dissertation, Technical Univ. Denmark, Lyngby, Denmark, 2003.

[15] Z. Lubosny, Wind Turbine Operation in Electric Power Systems. New York: Springer, 2003.

[16] M. Martins, A. Perdana, P. Ledesma, E. Agneholm, and O. Carlson, "Validation of fixed speed wind turbine dynamic models with measured data," Renew. Energy, vol. 32, no. 8, pp. 1301-1316, Jul. 2007.

[17] V. Akhmatov and A. H. Nielsen, "Fixed-speed active-stall wind turbines in offshore applications," Eur. Trans. Elect. Power, vol. 15, no. 1, pp. 1-12, 2005 .

[18] G. Rogdakis, R. Garcia-Valle, I. Arana, R. Sharma, and K. H. Jensen, "Electromagnetic validation of fault-ride through capabilities of wind turbines," in Proc. 9th Int. Workshop Large-Scale Integration of Wind Power into Power Systems as well as on Transmission Networks for Offshore Wind Power Plants, Oct. 2010.

[19] J. G. Duncan, M. S. Sarma, and T. O. Overbye, Power System Analysis and Design, 4th ed. Tampa, FL: Thomson, 2008.

[20] T. Kakinoki, R. Yokoyama, G. Fujita, K. Koyanagi, T. Funabashi, and K. Y. Lee, "Shaft torque observer and excitation control for tubinegenerator torsional oscillation," Elect. Power Syst. Res., vol. 68, pp. 248-257, 2004.
[21] M. Rahimi and M. Parniani, "Dynamic behavior and transient stability of fixed-speed wind turbines," Renew. Energy, vol. 34, pp. 2613-2624, 2009.

[22] ELSPEC, The EQUALIZER/ACTIVAR: Introduction, Installation, Operation and Troubleshooting, ELSPEC-Engineering Ltd., 2010, revision 7.

Georgios Rogdakis was born in Athens, Greece, in 1984. He received the Diploma in electrical and computer engineering from NTUA, Athens, Greece, in 2008 and the M.Sc. degree in wind energy from DTU, Denmark, in 2010.

$\mathrm{He}$ is currently employed at DONG Energy, Renewables, and his main field of work is integration of wind power into the power system and power quality.

Rodrigo García-Valle (S'99-M'08) received the electrical engineering degree from the National Polytechnic Institute of México, in 2001, the M.Sc. degree from CINVESTAV, Guadalajara, México, in 2003, and the Ph.D. degree from the University of Glasgow, Glasgow, U.K., in 2007.

In 2008, he was granted the Hans Christian Ørsted Award by DTU to carry out postdoctoral research activities. Since 2009, he has held the position of Assistant Professor. His research interests are dynamics, stability, and control of electric power systems; synchrophasor measurement devices for smart transmission grids; and renewable energy integration.

Dr. García-Valle is a member of IET and CIGRE.

Iván Arana (M’09) was born in Mexico City, Mexico, in 1983. He received the bachelor degree from ITESM, Mexico, in 2005 and M.Sc. degree from DTU, Denmark, in 2008. He is now pursuing the Industrial Ph.D. degree at the CET in cooperation with DONG Energy and Siemens Wind Power. 